\title{
Insulin-resistance and metabolic syndrome are related to executive function in women in a large family-based study
}

\author{
M. Schuur - P. Henneman - J. C. van Swieten - M. C. Zillikens • \\ I. de Koning - A. C. J. W. Janssens • J. C. M. Witteman - Y. S. Aulchenko • \\ R. R. Frants $\cdot$ B. A. Oostra $\cdot$ K. Willems van Dijk $\cdot$ C. M. van Duijn
}

Received: 9 January 2010/Accepted: 31 May 2010/Published online: 29 June 2010

(C) The Author(s) 2010. This article is published with open access at Springerlink.com

\begin{abstract}
While type 2 diabetes is well-known to be associated with poorer cognitive performance, few studies have reported on the association of metabolic syndrome (MetS) and contributing factors, such as insulin-resistance (HOMA-IR), low adiponectin-, and high C-reactive protein (CRP)- levels. We studied whether these factors are related
\end{abstract}

M. Schuur · P. Henneman · Y. S. Aulchenko

B. A. Oostra . C. M. van Duijn $(\bowtie)$

Genetic Epidemiology Unit Ee2173, Unit of the Departments of Epidemiology and Clinical Genetics, Erasmus MC University

Medical Center, PO Box 2040, 3000 CA Rotterdam,

The Netherlands

e-mail: c.vanduijn@erasmusmc.nl

M. Schuur

e-mail: m.schuur@erasmusmc.nl

M. Schuur · J. C. van Swieten · I. de Koning

Department of Neurology, Erasmus MC University Medical

Center, PO Box 2040, 3000 CA Rotterdam,

The Netherlands

P. Henneman · R. R. Frants · K. W. van Dijk

Department of Human Genetics, Leiden University Medical

Center, postal zone S-04-P, PO Box 9600, 2300 RC Leiden,

The Netherlands

M. C. Zillikens

Department of Internal Medicine, Erasmus MC University

Medical Center, PO Box 2040, 3000 CA Rotterdam,

The Netherlands

A. C. J. W. Janssens - J. C. M. Witteman

Department of Epidemiology, Erasmus MC University Medical Center, PO Box 2040, 3000 CA Rotterdam, The Netherlands

K. W. van Dijk

Department of Internal Medicine, Leiden University Medical Center, postal zone S-04-P, PO Box 9600, 2300 RC Leiden,

The Netherlands to cognitive function and which of the MetS components are independently associated. The study was embedded in an ongoing family-based cohort study in a Dutch population. All participants underwent physical examinations, biomedical measurements, and neuropsychological testing. Linear regression models were used to determine the association between MetS, HOMA-IR, adiponectin levels, CRP, and cognitive test scores. Cross-sectional analyses were performed in 1,898 subjects (mean age 48 years, $43 \%$ men). People with MetS had significantly higher HOMA-IR scores, lower adiponectin levels, and higher CRP levels. MetS and high HOMA-IR were associated with poorer executive function in women $(P=0.03$ and $P=0.009)$. MetS and HOMA-IR are associated with poorer executive function in women.

Keywords Cognition - Executive function .

Metabolic syndrome $\cdot$ Insulin-resistance $\cdot$ Adiponectin

\begin{tabular}{|c|c|}
\hline \multicolumn{2}{|c|}{ List of abbreviations } \\
\hline APOE & Apolipoprotein E gene \\
\hline ATPIII & $\begin{array}{l}\text { National Cholesterol Education Program } \\
\text { Adult Treatment Panel III }\end{array}$ \\
\hline CRP & C-reactive protein \\
\hline DART & Dutch Adult Reading Test \\
\hline FPA & Fasting plasma adiponectin \\
\hline ERF & Erasmus Rucphen Family Study \\
\hline HADS-D & Hospital Anxiety and Depression Scale \\
\hline HOMA-IR & $\begin{array}{l}\text { Homeostasis model assessment } \\
\text { insulin-resistance }\end{array}$ \\
\hline MetS & Metabolic syndrome \\
\hline RAVLT & Rey's Auditory Verbal Learning Test \\
\hline Stroop & Stroop Color and Word Test \\
\hline TMT & Trail Making Test \\
\hline
\end{tabular}




\section{Introduction}

Cognitive impairment is a common problem in the elderly and an important predictor of dementia (DSM-IV). There are multiple risk factors contributing to cognitive decline. For long, type 2 diabetes has been recognized as a major risk factor of dementia [1]. Epidemiological studies indicate that hyperinsulinemia and insulin-resistance, which characterize type 2 diabetes, may cause cognitive dysfunction [2, 3]. Insulin-resistance is also a feature of the metabolic syndrome (MetS) and there is increasing interest in the role of MetS in cognition. The syndrome is defined as the presence of at least 3 out of 5 factors, which include central obesity, hyperglycemia, hypertension, hypertriglyceridemia, and low high-density lipoprotein cholesterol (HDL-c) levels [4]. It has a high prevalence of over $22 \%$ in Western societies [5], and is an important risk factor of cardiovascular disease $[6,7]$. Potentially, MetS is an important, modifiable, determinant of cognitive pathology [8-10]. Previous studies have shown associations between cognitive dysfunction and MetS, but results are not consistent and predominantly concern elderly people [11]. Of its individual components, hypertension and hyperglycemia have proven to be the most consistent determinants of cognitive function in a recent review of published studies [12].

Adipose tissue also plays an important role in the etiology of MetS. Adipose tissue functions as endocrine tissue, among which secretion of adipocytokines and cytokines, which indirectly affect C-reactive protein (CRP) levels [13-15]. The visceral fat depot is thought to play an important role in adipocytokine secretion and MetS [16]. Several groups have suggested that in particular adiponectin might be a promising biomarker for MetS [17-19]. Whether it is related to cognitive function in humans is not known, but animal studies indicate that adiponectin may influence brain metabolism [20]. Regarding CRP levels, it has been reported that the association of MetS with cognitive function is stronger in those with high levels of CRP $[21,22]$.

The MetS is an important health problem and may be a suitable target for early intervention. The aim of the current study was to examine whether the MetS and related factors, insulin-resistance, plasma adiponectin and CRP-levels, are related to cognitive function in a middle-aged population in the Netherlands.

\section{Methods}

Study population

The study was performed in the Erasmus Rucphen Family Study (ERF), which is an ongoing family-based cohort study in a genetically isolated population [23]. The ERF population includes around 3,000 individuals, all living descendents of 22 couples who, at the end of the $19^{\text {th }}$ century had at least six children baptized in the community church. Extensive data on cardiovascular risk factors, body composition, cognitive functioning, and blood chemistry are available. These data were collected between 2002 and 2005. All participants gave informed consent and the study was approved by the Medical Ethics Committee at ErasmusMC.

\section{Clinical and laboratory assessments}

To define MetS, we used the definition proposed by the National Cholesterol Education Program Adult Treatment Panel (ATPIII) [4]. Waist circumference was measured exactly halfway the distance between the lower costal margin and the iliac crest [24]. Blood pressure was measured twice with an automatic device in a sitting position [25].

Blood was taken after fasting of at least $8 \mathrm{~h}$. Insulinresistance was determined as homeostasis model assessment insulin-resistance (HOMA-IR) [26], which was computed by multiplying fasting plasma insulin (micro-international units per milliliter) and fasting plasma glucose (millimoles per liter)/22.5. Total plasma adiponectin was analyzed with the Human adiponectin RIA kit (cat.\#: HADP-61HK) of Linco Research. To measure total plasma CRP, we used the US C-reactive protein ELISA (cat.\# DSL-10-42100) of Diagnostic Systems Laboratories, Inc.

We considered age, gender, smoking, alcohol use, education, depression, and Apolipoprotein E genotype (APOE) as possible confounders. Use of alcohol was defined as drinking at least 1 glass each day. Education was categorized in four groups: the first group corresponding to 6 years of education; the second to 7-10 years; the third to 1114 years; and the fourth to 15-18 years. Depressive symptoms were measured with the Hospital Anxiety and Depression Scale (HADS-D). Genomic DNA was extracted from whole blood samples, utilizing the salting out method. Samples were genotyped for APOE with a Taqman allelic discrimination Assay-By-Design (Applied Biosystems, Foster City, CA). Insulin and adiponectin were only measured in a random subsample because of financial constraints, therefore these data were not available for 721 participants.

\section{Cognitive function}

The battery of neuropsychological tests measured different cognitive domains $[27,28]$. General cognitive ability was assessed with the Dutch Adult Reading Test (DART). Memory function was measured with the auditory verbal learning test from which four scores were derived: 
immediate memory; learning; delayed recall, defined as the number of correctly recalled words after $20 \mathrm{~min}$; and recognition, defined as the number of correctly recognized and correctly rejected words. Executive function was assessed with the Trail Making Test parts A and B (TMT), the Stroop Color and Word Test cards I, II and III, and verbal fluency tests. The TMT is a time-demanding task in which participants are asked to connect a randomly placed series of letters and numbers as quickly as possible [29]. In TMT-A only the numbers have to be connected, in TMT-B numbers and letters have to be connected alternately (from 1 to $\mathrm{A}$, to 2 to $\mathrm{B}$ etc.). For analysis, we used time in seconds depicted as the ratio of TMT-B/TMT-A. The Stroop Color and Word Test is also a time demanding task consisting of three cards. In card I, participants have to name the right words as quickly as possible, in card II they have to name the right colors as quickly as possible and in card III they have to name the colors in which the words are printed as quickly as possible. On this card the meaning of the word is different than the color the word is printed in (e.g. blue is written whereas the word is printed in red) [30]. For analyses, we used time in seconds depicted as the ratios of Stroop-III/Stroop-II. In the verbal fluency tests, participants had to name as many animals and as many words starting with the same letter (D, A and T), each in $1 \mathrm{~min}$. The score was defined as the total number of correct words on both tasks. Lastly, visuo-spatial ability was assessed with the WAIS-III block-design subtest. The test consists of reproducing two-dimensional patterns using cubes that have red, white, and half-red-half-white faces. The total number of correctly reproduced blocks within a time limit was used as a score.

In addition to analyzing individual test scores, three composite scores were used: (1) memory (z-memory); (2) executive function (z-executive); (3) global cognition ( $z$-global). These scores were computed by taking the average of $z$-scores of the individual tests, which were computed by subtracting the mean from the test score divided by the standard deviation [31]. For time-demanding tasks, the test score was subtracted from the mean. The composite scores were only computed when at least 3 memory scores (z-memory), 2 executive scores ( $z$-executive) and 6 total test scores ( $z$-global) were available. In the current study, we excluded participants who had a history of stroke or dementia $(N=21)$ or were physically not able to perform a neuropsychological test $(N=44)$. There were 10 participants with missing test scores due to technical problems.

\section{Statistical analysis}

One large pedigree was extracted from the genealogical database, which was cut into smaller pedigrees before analyses with the software PedCut [32]. In total, 1,898 people with complete data could be linked to pedigrees with a maximum bit size of 18 and these were included in the analyses.

Baseline descriptive analyses were performed with SPSS version 15.0, using the independent-samples $T$-test (continuous variables) or Chi-square statistics (categorical data). C-reactive protein levels were transformed by taking the common logarithm. Because high levels of CRP could have been caused by acute inflammation, all values of the logtransformed variable greater than three times the standard deviation above the mean were excluded.

Possible confounders were first analyzed as single covariates in two regression models with either MetS or cognitive test scores as dependent variables. Also, interaction terms of MetS, HOMA-IR, adiponectin and CRP with age and sex were analyzed in these models. Covariates that were significantly associated were then entered simultaneously into a model using backward regression. We removed all covariates with a $P$-value $>0.10$. The final model included age, level of education, HADS-D score, alcohol use and inbreeding coefficient, which is a measure of relatedness of the parents of an individual. The analyses were stratified by sex, because the interaction terms of MetS with sex were significant.

To identify associations between cognitive test scores and MetS, HOMA-IR, adiponectin, and CRP, we performed regression analyses using the SOLAR software version 4.1.0 [33]. The MetS was included in the model as a binomial variable, and additionally as a continuous variable ranging from 0 to 5 to test the effect of increasing number of MetS components. We used quartiles of HOMA-IR, adiponectin and CRP with the lowest quartile as a reference category to estimate the association with adipose tissue endocrine function.

\section{Results}

The mean age of the study population was $47.7( \pm 14.3)$ years in women and $49.2( \pm 14.1)$ years in men, with a range of 18-86 years and less than $10 \%$ older than 67 . Metabolic syndrome was present in $227(21 \%)$ women and in $207(25 \%)$ men. Of these, 155 women and 150 men fulfilled three of the MetS diagnostic criteria, 63 and 54 fulfilled four and 9 and 3 fulfilled all five. Null criteria were fulfilled by 282 women and 153 men. A comparison of the individual MetS components is given in Table 1.

Table 2 shows the baseline characteristics of men and women with and without MetS regarding determinants of cognitive function and vascular and endocrine factors.

We studied the associations between MetS and cognitive test scores. Women with MetS had significantly lower scores 
Table 1 Metabolic syndrome in the Erasmus rucphen family study $(n=1,898)$

\begin{tabular}{|c|c|c|c|c|}
\hline & \multicolumn{2}{|l|}{ Men } & \multicolumn{2}{|l|}{ Women } \\
\hline & MetS absent $(n=615)$ & MetS present $(n=207)$ & MetS absent $(n=849)$ & MetS present $(n=227)$ \\
\hline \multicolumn{5}{|l|}{ MetS components } \\
\hline Waist circumference $(\mathrm{cm})$ & $90.1(9.5)$ & $105.1(9.3)$ & $78.2(9.5)$ & $94.5(10.2)$ \\
\hline $\mathrm{SBP}(\mathrm{mm} \mathrm{Hg})$ & $140.7(17.2)$ & $151.2(17.3)$ & $131.2(18.4)$ & $152.9(21.0)$ \\
\hline $\mathrm{DBP}(\mathrm{mm} \mathrm{Hg})$ & $80.3(9.5)$ & $85.5(9.4)$ & $76.8(9.3)$ & $84.0(10.0)$ \\
\hline Use of antihypertensive medication (\%) & 11.7 & 34.3 & 9.0 & 38.3 \\
\hline Glucose (mmol/L, FPG) & $4.6(0.8)$ & $5.2(1.4)$ & $4.3(0.7)$ & $5.1(1.1)$ \\
\hline Use of antidiabetic medication (\%) & 0.7 & 9.7 & 0.2 & 8.8 \\
\hline HDL-cholesterol (mmol/L) & $1.2(0.3)$ & $0.9(0.2)$ & $1.5(0.4)$ & $1.2(0.3)$ \\
\hline Triglycerides (mmol/L) & $1.2(0.6)$ & $2.3(1.0)$ & $1.1(0.5)$ & $1.8(0.8)$ \\
\hline Use of statins (\%) & 11.4 & 25.6 & 5.9 & 25.6 \\
\hline
\end{tabular}

Values presented as mean (standard deviation). MetS = metabolic syndrome

Table 2 Metabolic Syndrome in relation to vascular and endocrine factors and determinants of cognitive function

\begin{tabular}{|c|c|c|c|c|}
\hline & \multicolumn{2}{|l|}{ Men } & \multicolumn{2}{|l|}{ Women } \\
\hline & MetS absent $(n=615)$ & MetS present $(n=207)$ & MetS absent $(n=849)$ & MetS present $(n=227)$ \\
\hline \multicolumn{5}{|l|}{ Vascular and endocrine factors } \\
\hline Smoking (\%) & 32.7 & 33.5 & 46.5 & 45.1 \\
\hline Insulin $(\mu \mathrm{U} / \mathrm{ml}, \mathrm{FPI})$ & $11.8(5.6)$ & $19.1(11.1)^{* *}$ & $11.5(4.7)$ & $18.0(9.2)^{* *}$ \\
\hline HOMA-IR & $2.4(1.4)$ & $4.5(2.9) * *$ & $2.2(1.0)$ & $4.1(2.4)^{* *}$ \\
\hline Adiponectin (mg/L) & $8.5(4.2)$ & $6.7(3.7)^{* *}$ & $13.1(5.8)$ & $9.5(4.6)^{* *}$ \\
\hline CRP (mg/L) & $3.1(6.2)$ & $3.5(5.8)^{* *}$ & $3.4(5.4)$ & $5.1(7.4)^{* *}$ \\
\hline \multicolumn{5}{|l|}{ Determinants of cognitive function } \\
\hline Age (year) & $47.4(14.3)$ & $54.4(11.9) * *$ & $45.3(13.7)$ & $56.7(12.6)^{* *}$ \\
\hline Education level (\%) & & $* *$ & & $* *$ \\
\hline Low & 30.0 & 37.7 & 26.2 & 46.9 \\
\hline Low-intermediate & 37.9 & 44.4 & 42.0 & 40.7 \\
\hline High-intermediate & 24.1 & 14.5 & 27.3 & 11.5 \\
\hline High & 8.0 & 3.4 & 4.5 & 3.7 \\
\hline Alcohol (\% frequent users) $\S$ & 45.0 & $36.6 *$ & 19.9 & $12.9 *$ \\
\hline HADS-D score & $5.7(4.0)$ & $6.4(3.8) *$ & $5.4(4.2)$ & $7.6(4.6)^{* *}$ \\
\hline Apoe 4 allele carriers $(\%)$ & 36.3 & 42.6 & 35.5 & 40.3 \\
\hline
\end{tabular}

Values presented as mean (standard deviation)

$M e t S$ metabolic syndrome, FPG fasting plasma glucose, FPI fasting plasma insulin, HOMA-IR homeostatic assessment-insulin resistant model, $H A D S-D$ Hospital Anxiety and Depression Scale, $\S$ defined as drinking at least one unit of alcohol per day. $*$ unadjusted $P$-value $<0.05$; ** unadjusted $P$-value $<0.01$

on Stroop en $\mathrm{z}$-executive $(P=0.03$ and $P=0.02)$ than women without MetS (Table 3). An increasing number of MetS components was associated to lower verbal fluency and $z$-executive scores $(P=0.04$ and 0.02$)$ in women. The same trend, however non-significant $(P=0.10)$, was seen for Stroop.

The findings related to adipose tissue endocrine function are given in Fig. 1 with analyses limited to executive function. Women with high HOMA-IR scores had lower scores on TMT, Stroop and z-executive than women with low HOMA-IR scores. Higher adiponectin levels were associated with higher scores on $z$-executive in both men and women and with Stroop in women only. The associations of HOMA-IR with Stroop and z-executive were more significant $(P=0.004$ and 0.007$)$ when analyzing HOMA-IR as continuous variables instead of quartiles. The 
Table 3 Association metabolic syndrome and cognitive function in men and women

\begin{tabular}{|c|c|c|c|c|c|c|}
\hline \multirow[t]{2}{*}{ Cognitive test } & \multicolumn{3}{|c|}{ Men } & \multicolumn{3}{|c|}{ Women } \\
\hline & $n$ & MetS absent & MetS present & $n$ & MetS absent & MetS present \\
\hline \multicolumn{7}{|l|}{ General cognitive ability } \\
\hline Dutch adult reading test & 750 & $62.1(19.0)$ & $58.3(18.5)$ & 993 & $60.4(18.2)$ & $52.6(18.1)$ \\
\hline \multicolumn{7}{|l|}{ Memory } \\
\hline AVLT_-Working memory & 757 & $4.3(1.7)$ & $3.9(1.5)$ & 999 & $4.6(1.7)$ & $4.0(1.6)$ \\
\hline AVLT_Learning & 757 & $32.1(8.9)$ & $29.2(8.3)$ & 999 & $35.5(8.9)$ & $31.8(8.9)$ \\
\hline AVLT—Recognition & 759 & $27.7(2.2)$ & $27.1(2.5)$ & 1,000 & $28.3(2.2)$ & $27.7(2.4)$ \\
\hline AVLT_Delayed recall & 759 & $7.1(2.9)$ & $6.4(2.8)$ & 1,000 & $8.3(2.9)$ & $7.2(2.9)$ \\
\hline \multicolumn{7}{|l|}{ Executive } \\
\hline Ratio TMT-B/TMT-A ${ }^{\mathrm{a}}$ & 752 & $2.7(1.0)$ & $2.8(1.0)$ & 996 & $2.6(1.0)$ & $2.9(1.1)$ \\
\hline Ratio stroop III/stroop II ${ }^{\mathrm{a}}$ & 734 & $1.7(0.4)$ & $1.8(0.4)$ & 996 & $1.7(0.3)$ & $1.9(0.6) *$ \\
\hline Verbal fluency & 758 & $63.7(18.0)$ & $60.0(17.1)$ & 998 & $63.0(17.9)$ & $53.5(18.7)$ \\
\hline \multicolumn{7}{|l|}{ Visuospatial } \\
\hline Block design & 756 & $30.8(15.6)$ & $25.7(13.9)$ & 998 & $28.7(15.1)$ & $20.8(11.2)$ \\
\hline \multicolumn{7}{|l|}{ Composite scores } \\
\hline Memory function & 757 & $0.1(0.8)$ & $-0.2(0.8)$ & 999 & $0.1(0.8)$ & $-0.3(0.9)$ \\
\hline Executive function & 759 & $0.1(0.7)$ & $-0.1(0.7)$ & 998 & $0.1(0.6)$ & $-0.4(0.8) *$ \\
\hline Global cognitive function & 758 & $0.1(0.7)$ & $-0.2(0.6)$ & 998 & $0.1(0.7)$ & $-0.3(0.7)$ \\
\hline
\end{tabular}

Values presented as mean (standard deviation). AVLT Adult Verbal Learning Test, TMT Trail Making Test, Stroop Stroop Color and Word Test

a time demanding task: high values represent low test scores

$P=P$-value derived from regression analysis adjusted for age, education, depressive score, alcohol use and family-relationship. * $P<0.05$

other associations, however, became non-significant. No association between CRP and executive function was found in this population.

\section{Discussion}

The main finding of the current study is that MetS and HOMA-IR is associated with poorer executive performance in women.

There a number of limitations of the study to be discussed before interpretation of the findings. The differences between persons with and without the MetS were relatively small, which makes the clinical relevance or our findings difficult to predict. Also, we performed many tests. Although statistically these tests are not independent, some of the significant $P$-values could be false-positive findings. When applying strict Bonferonni adjustment, our results are at best only borderline significant $\left(\mathrm{p}_{\text {homa-ir }}=0.11\right)$. We did not a priori have an hypothesis which of the different cognitive outcomes were associated. The finding of a relation to executive function but not to memory remains to be interpreted with caution. Although some are more consistent that others, the consistent associations argue against false-positive findings. The cross-sectional design is another limitation of our study, making it difficult to assess causality.
Several longitudinal studies, however, suggest that MetS might be a causative factor in the relationship with cognition [34]. Another point to be discussed is that we studied the relationship of MetS and cognition in a genetically isolated population. We have taken relatedness into account by adjusting for pedigree structure and relatedness, and since it is a recently isolated population, the genetic makeup does not differ largely from the general population and we do not expect large differences in the effects of cardiovascular risk factors on cognition [35]. As to the generalizaibility, there is no reason to assume that the findings in terms of the etiological pathways uncovered should not aply to outbred populations. However, the associations may be more or less pronounced in this family-based study. The strength of this study is the population-based design in which participants were not selected on the disease of interest. Also, the inclusion of a large sample size and a range of cognitive tests allowed detailed study of cognition.

Our findings of association of MetS with cognitive performance confirms previous cross-sectional and longitudinal studies [22, 36, 37]. Although we studied different cognitive domains, mainly executive function was associated with MetS. This is in line with two recent studies that found significant differences in processing speed, semantic fluency and executive function between persons with and without MetS [38, 39]. Associations of the MetS with 


\section{MEN}
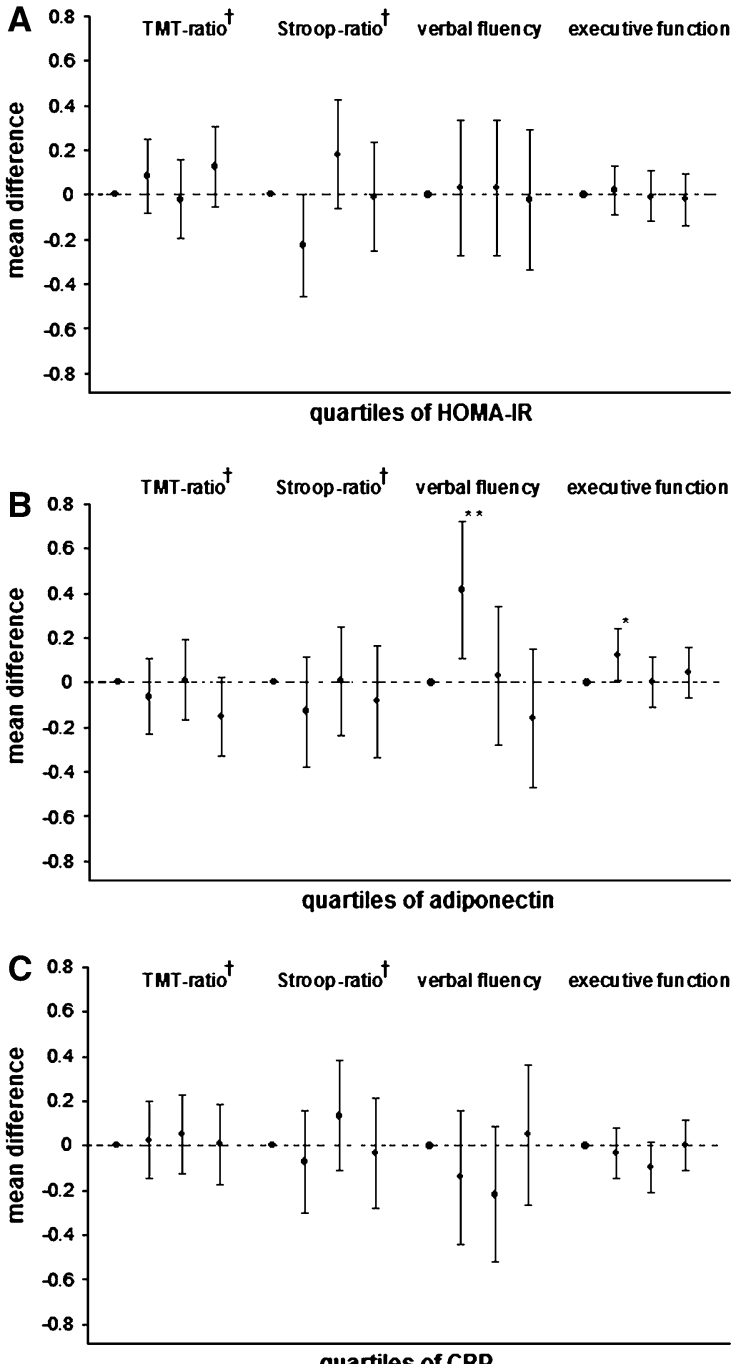

quartiles of CRP

Fig. 1 Associations of HOMA-IR (a), adiponectin (b), and CRP (c) with cognitive function in men and women Results are presented as mean differences compared to quartile 1 . The differences are adjusted for age, education, depressive score, alcohol use and family-

fronto-subcortical syndrome and with frontal white matter changes were found by others [10, 40]. Damage to cerebral small vessels could be one of the explanations for the observed associations in the current study [41-43] and also why we find an association with executive function and not memory. A number of studies find that an increasing number of MetS components is associated with lower cognitive scores, which is also confirmed by our observations [10, 37].

An effect of MetS components on the early development of Alzheimer's disease (AD) pathology may be another possible mechanism underlying our observations, since the insulin-degrading enzyme (IDE) functions less well in the presence of insulin-resistance, resulting in higher levels of amyloid $\beta$-peptide $(\mathrm{A} \beta)$ [44, 45]. Long-term exposure to insulin due to insulin-resistance, may by itself also have a
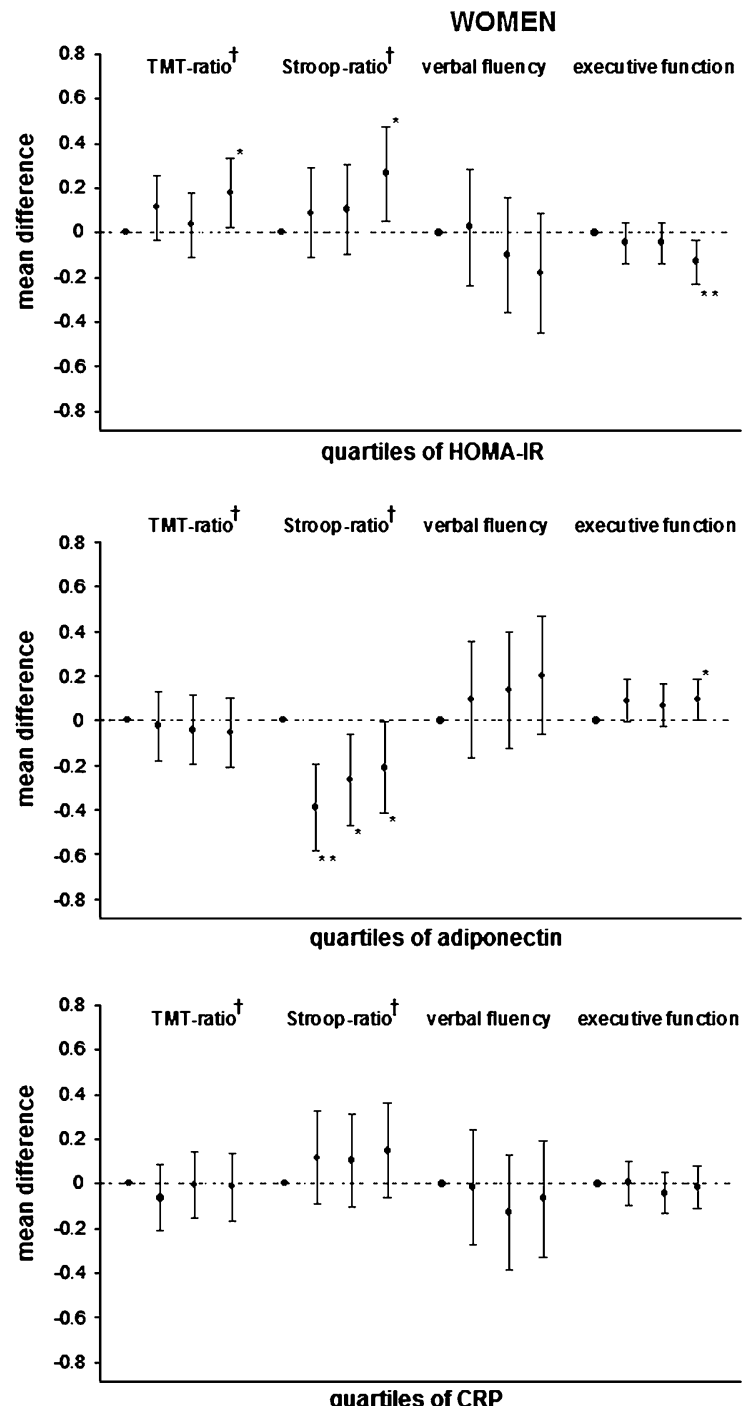

relationship. HOMA-IR $=$ homeostatis model assessment insulinresistance, $\mathrm{CRP}=\mathrm{C}$-reactive protein $* P$-value $<0.05 ; * * P$-value $<$ 0.01

direct damaging effect on neurons [46]. Our observed association of HOMA-IR and executive function is in line with this.

Despite possible pathways through which adiponectin could be linked to cognition, such as improvement of insulin-sensitivity, anti-inflammatory effects and effects on brain metabolism and the vascular system, our results do not show a consistent association of adiponectin with cognition [47, 48]. Adiponectin levels are however, lower in individuals with MetS in our study and a trend was seen with executive function in women, which supports further study on the role of adiponectin in cognition.

Levels of CRP were not related to cognition in the present study, however, data on other markers, such as interleukin-6 (Il-6) and $\alpha 1$-antichymotrypsin (ACT) were 
not available. These markers have been related to cognitive decline and increased systemic inflammation has been proposed as a possible modifier between MetS and cognition [22]. We could not confirm this, which may also be due to a more pronounced effect of inflammation on cognition in the elderly than in middle aged individuals.

Our study shows that there are gender differences in the association of MetS with cognitive function. Gender-specific effects of metabolic components on cognitive function have not extensively been addressed in previous studies, while there is evidence that MetS has greater effect on cardiovascular and cerebrovascular disease in women than in men, indirectly supporting our observed differences $[49,50]$. Furthermore, there is evidence that men are treated more aggressively for cardiovascular risk factors [51]. As a consequence, men may be less likely to experience the adverse effects of MetS. Another factor that could explain gender differences is depression, which is highly correlated to cognition and more common in women. Since our analyses were adjusted for depressive symptoms, however, we do not think that depression explains the observed differences in our study.

In summation, the most important findings of our study are that MetS and HOMA-IR are associated with executive function in women. We interpret these results with caution due to the cross-sectional design and the potential problems related to multiple testing. However, our study yields an important starting point to replicate these findings and take them further. Longitudinal studies will be needed to gain insight in the causality of our reported findings and may result in more conclusive findings.

Acknowledgments This study is financially supported by the Netherlands Organization for Scientific Research (NWO), the Nutrigenomics Consortium (NGC) and the Centre for Medical Systems Biology (CMSB) in the framework of the Netherlands Genomics Initiative (NGI). We thank Marijke Frolich of the dept. Clinical Chemistry, Leiden University Medical Center, for measuring plasma adiponectin, CRP and insulin levels.

Open Access This article is distributed under the terms of the Creative Commons Attribution Noncommercial License which permits any noncommercial use, distribution, and reproduction in any medium, provided the original author(s) and source are credited.

\section{References}

1. Ott A, Stolk RP, van Harskamp F, Pols HA, Hofman A, Breteler MM. Diabetes mellitus and the risk of dementia: the Rotterdam study. Neurology. 1999;53:1937-42.

2. Geroldi C, Frisoni GB, Paolisso G, Bandinelli S, Lamponi M, Abbatecola AM, Zanetti O, Guralnik JM, Ferrucci L. Insulin resistance in cognitive impairment: the InCHIANTI study. Arch Neurol. 2005;62:1067-72.

3. Young SE, Mainous AG 3rd, Carnemolla M. Hyperinsulinemia and cognitive decline in a middle-aged cohort. Diabetes Care. 2006;29:2688-93.
4. Grundy SM, Cleeman JI, Daniels SR, Donato KA, Eckel RH, Franklin BA, Gordon DJ, Krauss RM, Savage PJ, Smith SC Jr, Spertus JA, Costa F. Diagnosis and management of the metabolic syndrome: an American heart association/national heart, lung, and blood institute scientific statement. Circulation. 2005;112: 2735-52.

5. Ford ES, Giles WH, Dietz WH. Prevalence of the metabolic syndrome among US adults: findings from the third national health and nutrition examination survey. Jama. 2002;287:356-9.

6. Alberti KG, Zimmet P, Shaw J, IDFETFC Group. The metabolic syndrome - a new worldwide definition. Lancet. 2005;366:1059-62.

7. Olijhoek JK, van der Graaf Y, Banga JD, Algra A, Rabelink TJ, Visseren FL, The SSG. The metabolic syndrome is associated with advanced vascular damage in patients with coronary heart disease, stroke, peripheral arterial disease or abdominal aortic aneurysm. Eur Heart J. 2004;25:342-8.

8. Kwon HM, Kim BJ, Lee SH, Choi SH, Oh BH, Yoon BW. Metabolic syndrome as an independent risk factor of silent brain infarction in healthy people. Stroke. 2006;37:466-70.

9. Kumari M, Brunner E, Fuhrer R. Minireview: mechanisms by which the metabolic syndrome and diabetes impair memory. J Gerontol A Biol Sci Med Sci. 2000;55:B228-32.

10. Roriz-Cruz M, Rosset I, Wada T, Sakagami T, Ishine M, De Sa Roriz-Filho J, Cruz TR, Hosseinkhani M, Rodrigues RP, Sudoh S, Arai H, Wakatsuki Y, Souza AC, Nakagawa M, Kita T, Matsubayashi K. Cognitive impairment and frontal-subcortical geriatric syndrome are associated with metabolic syndrome in a stroke-free population. Neurobiol Aging. 2007;28:1723-36.

11. Yaffe K, Weston AL, Blackwell T, Krueger KA. The metabolic syndrome and development of cognitive impairment among older women. Arch Neurol. 2009;66:324-8.

12. van den Berg E, Kloppenborg RP, Kessels RP, Kappelle LJ, Biessels GJ. Type 2 diabetes mellitus, hypertension, dyslipidemia and obesity: a systematic comparison of their impact on cognition. Biochim Biophys Acta. 2009;1792:470-81.

13. Devaraj S, Torok N, Dasu MR, Samols D, Jialal I. Adiponectin decreases C-reactive protein synthesis and secretion from endothelial cells: evidence for an adipose tissue-vascular loop. Arterioscler Thromb Vasc Biol. 2008;28:1368-74.

14. Guerre-Millo M. Adipose tissue and adipokines: for better or worse. Diabetes Metab. 2004;30:13-9.

15. Rader DJ. Inflammatory markers of coronary risk. N Engl J Med. 2000;343:1179-82.

16. Bacha F, Saad R, Gungor N, Arslanian SA. Adiponectin in youth: relationship to visceral adiposity, insulin sensitivity, and beta-cell function. Diabetes Care. 2004;27:547-52.

17. Gilardini L, McTernan PG, Girola A, da Silva NF, Alberti L, Kumar S, Invitti C. Adiponectin is a candidate marker of metabolic syndrome in obese children and adolescents. Atherosclerosis. 2006;189:401-7.

18. Luchsinger JA. Adiposity, hyperinsulinemia, diabetes and Alzheimer's disease an epidemiological perspective. Eur J Pharmacol 2008.

19. Lara-Castro C, Fu Y, Chung BH, Garvey WT. Adiponectin and the metabolic syndrome: mechanisms mediating risk for metabolic and cardiovascular disease. Curr Opin Lipidol. 2007;18:263-70.

20. Kubota N, Yano W, Kubota T, Yamauchi T, Itoh S, Kumagai H, Kozono H, Takamoto I, Okamoto S, Shiuchi T, Suzuki R, Satoh H, Tsuchida A, Moroi M, Sugi K, Noda T, Ebinuma H, Ueta Y, Kondo T, Araki E, Ezaki O, Nagai R, Tobe K, Terauchi Y, Ueki K, Minokoshi Y, Kadowaki T. Adiponectin stimulates AMPactivated protein kinase in the hypothalamus and increases food intake. Cell Metab. 2007;6:55-68.

21. Yaffe K. Metabolic syndrome and cognitive disorders: is the sum greater than its parts? Alzheimer Dis Assoc Disord. 2007;21: $167-71$. 
22. Dik MG, Jonker C, Comijs HC, Deeg DJ, Kok A, Yaffe K, Penninx BW. Contribution of metabolic syndrome components to cognition in older individuals. Diabetes Care. 2007;30:2655-60.

23. Aulchenko YS, Heutink P, Mackay I, Bertoli-Avella AM, Pullen J, Vaessen N, Rademaker TA, Sandkuijl LA, Cardon L, Oostra B, van Duijn CM. Linkage disequilibrium in young genetically isolated Dutch population. Eur J Hum Genet. 2004;12:527-34.

24. Santos RL, Zillikens MC, Rivadeneira FR, Pols HA, Oostra BA, van Duijn CM, Aulchenko YS. Heritability of fasting glucose levels in a young genetically isolated population. Diabetologia. 2006;49:667-72.

25. Sleegers K, de Koning I, Aulchenko YS, van Rijn MJ, Houben MP, Croes EA, van Swieten JC, Oostra BA, van Duijn CM. Cerebrovascular risk factors do not contribute to genetic variance of cognitive function: the ERF study. Neurobiol Aging. 2007; 28:735-41.

26. Matthews DR, Hosker JP, Rudenski AS, Naylor BA, Treacher DF, Turner RC. Homeostasis model assessment: insulin resistance and beta-cell function from fasting plasma glucose and insulin concentrations in man. Diabetologia. 1985;28:412-9.

27. Sleegers K, Roks G, Theuns J, Aulchenko YS, Rademakers R, Cruts M, van Gool WA, Van Broeckhoven C, Heutink P, Oostra BA, van Swieten JC, van Duijn CM. Familial clustering and genetic risk for dementia in a genetically isolated Dutch population. Brain. 2004;127:1641-9.

28. Liu F, Pardo LM, Schuur M, Sanchez-Juan P, Isaacs A, Sleegers K, de Koning I, Zorkoltseva IV, Axenovich TI, Witteman JC, Janssens AC, van Swieten JC, Aulchenko YS, Oostra BA, van Duijn CM. The apolipoprotein E gene and its age-specific effects on cognitive function. Neurobiol Aging 2008.

29. Reitan RM. The relation of the trail making test to organic brain damage. J Consult Clin Psychol. 1955;19:393-4.

30. Hammes J. Stroop kleur-woord test: Dutch manual. Lisse, The Netherlands: Swets and Zeitlinger BV; 1978.

31. Prins ND, van Dijk EJ, den Heijer T, Vermeer SE, Jolles J, Koudstaal PJ, Hofman A, Breteler MM. Cerebral small-vessel disease and decline in information processing speed, executive function and memory. Brain. 2005;128:2034-41.

32. Liu F, Kirichenko A, Axenovich TI, van Duijn CM, Aulchenko YS. An approach for cutting large and complex pedigrees for linkage analysis. Eur J Hum Genet. 2008;16:854-60.

33. Almasy L, Blangero J. Multipoint quantitative-trait linkage analysis in general pedigrees. Am J Hum Genet. 1998;62: 1198-211.

34. Yaffe K, Kanaya A, Lindquist K, Simonsick EM, Harris T, Shorr RI, Tylavsky FA, Newman AB. The metabolic syndrome, inflammation, and risk of cognitive decline. JAMA. 2004;292: 2237-42.

35. Pardo LM, MacKay I, Oostra B, van Duijn CM, Aulchenko YS. The effect of genetic drift in a young genetically isolated population. Ann Hum Genet. 2005;69:288-95.

36. Komulainen P, Lakka TA, Kivipelto M, Hassinen M, Helkala EL, Haapala I, Nissinen A, Rauramaa R. Metabolic syndrome and cognitive function: a population-based follow-up study in elderly women. Dement Geriatr Cogn Disord. 2007;23:29-34.

37. Yaffe K, Haan M, Blackwell T, Cherkasova E, Whitmer RA, West N. Metabolic syndrome and cognitive decline in elderly
Latinos: findings from the Sacramento area Latino study of aging study. J Am Geriatr Soc. 2007;55:758-62.

38. van den Berg E, Dekker JM, Nijpels G, Kessels RP, Kappelle LJ, de Haan EH, Heine RJ, Stehouwer CD, Biessels GJ. Cognitive functioning in elderly persons with type 2 diabetes and metabolic syndrome: the Hoorn study. Dement Geriatr Cogn Disord. 2008;26:261-9.

39. Segura B, Jurado MA, Freixenet N, Albuin C, Muniesa J, Junque C. Mental slowness and executive dysfunctions in patients with metabolic syndrome. Neurosci Lett. 2009;462:49-53.

40. Segura B, Jurado MA, Freixenet N, Falcon C, Junque C, Arboix A. Microstructural white matter changes in metabolic syndrome: a diffusion tensor imaging study. Neurology. 2009;73:438-44.

41. O'Brien JT, Wiseman R, Burton EJ, Barber B, Wesnes K, Saxby B, Ford GA. Cognitive associations of subcortical white matter lesions in older people. Ann N Y Acad Sci. 2002;977:436-44.

42. van Dijk EJ, Breteler MM, Schmidt R, Berger K, Nilsson LG, Oudkerk M, Pajak A, Sans S, de Ridder M, Dufouil C, Fuhrer R, Giampaoli S, Launer LJ, Hofman A, Consortium C. The association between blood pressure, hypertension, and cerebral white matter lesions: cardiovascular determinants of dementia study. Hypertension. 2004;44:625-30.

43. Pa J, Boxer A, Chao LL, Gazzaley A, Freeman K, Kramer J, Miller BL, Weiner MW, Neuhaus J, Johnson JK. Clinical-neuroimaging characteristics of dysexecutive mild cognitive impairment. Ann Neurol. 2009;65:414-23.

44. Farris W, Mansourian S, Leissring MA, Eckman EA, Bertram L, Eckman CB, Tanzi RE, Selkoe DJ. Partial loss-of-function mutations in insulin-degrading enzyme that induce diabetes also impair degradation of amyloid beta-protein. Am J Pathol. 2004;164: 1425-34.

45. Craft S. Insulin resistance syndrome and Alzheimer's disease: age- and obesity-related effects on memory, amyloid, and inflammation. Neurobiol Aging. 2005;26(Suppl 1):65-9.

46. Li ZG, Zhang W, Grunberger G, Sima AA. Hippocampal neuronal apoptosis in type 1 diabetes. Brain Res. 2002;946:221-31.

47. Han SH, Sakuma I, Shin EK, Koh KK. Antiatherosclerotic and anti-insulin resistance effects of adiponectin: basic and clinical studies. Prog Cardiovasc Dis. 2009;52:126-40.

48. Kubota N, Yano W, Kubota T, Yamauchi T, Itoh S, Kumagai H, Kozono H, Takamoto I, Okamoto S, Shiuchi T, Suzuki R, Satoh H, Tsuchida A, Moroi M, Sugi K, Noda T, Ebinuma H, Ueta Y, Kondo T, Araki E, Ezaki O, Nagai R, Tobe K, Terauchi Y, Ueki K, Minokoshi Y, Kadowaki T. Adiponectin stimulates AMPactivated protein kinase in the hypothalamus and increases food intake. Cell Metab. 2007;6:55-68.

49. Pischon T, Hu FB, Rexrode KM, Girman CJ, Manson JE, Rimm EB. Inflammation, the metabolic syndrome, and risk of coronary heart disease in women and men. Atherosclerosis. 2008;197:392-9.

50. McNeill AM, Rosamond WD, Girman CJ, Golden SH, Schmidt MI, East HE, Ballantyne CM, Heiss G. The metabolic syndrome and 11-year risk of incident cardiovascular disease in the atherosclerosis risk in communities study. Diabetes Care. 2005;28:385-90.

51. Gouni-Berthold I, Berthold HK, Mantzoros CS, Bohm M, Krone W. Sex disparities in the treatment and control of cardiovascular risk factors in type 2 diabetes. Diabetes Care. 2008;31:1389-91. 